\title{
Peculiarities of Mineral Metabolism of Holstein Heifers' Diet Supplemented with Copper Nanopowders
}

\author{
Irina A. Stepanova ${ }^{1 *}$, Anna A. Nazarova ${ }^{2}$, and Mikhail V. Arisov ${ }^{1}$ \\ ${ }^{I}$ All-Russian Scientific Research Institute of Fundamental and Applied Parasitology of Animals and Plants named after K.I. Skryabin -Branch of the \\ Federal State Budget Scientific Institution «Federal Scientific Center-All-Russian Scientific Research Institute of Experimental Veterenari Medicina \\ K.I. Skryabin and Y.R. Kovalenko the Russian Academy of Sciences», B. Cheremushkinskaya Street 28, 117218 Moscow, Russia \\ ${ }^{2}$ Ryazan State Agrotechnological University named after P.A. Kostychev, 1, Kostychev Street 1, 390044, Ryazan, Russia \\ *Corresponding author's Email: irinkastepanova@yandex.ru; (DORCiD: 0000-0002-1316-398X
}

\begin{abstract}
The current study aimed to investigate the effect of copper nanopowder on physiological and mineral metabolism indicators of Holstein cattle during the growth process of the animal. There were two experimental groups (control and treatment) and each one included seven Holstein heifers. From the first month of each heifer in the experimental group, a suspension of copper nanoparticles in a dose of $0.04 \mathrm{mg} / \mathrm{kg}$ was orally administered daily to the usual diet. The biologically active additive was administered to the animal's diet at intervals. The weight of the animals was measured monthly, a clinical blood test was performed, the mineral composition of the blood was studied, the mineral composition of animal hair was also examined. The findings indicated a positive dynamics in the increase of body weight in the treatment group, compared to the control group. As a result of clinical blood tests, it was noted that the number of erythrocytes, the level of hemoglobin, and hematocrit increased in the experimental animals due to copper nanoparticles compared to these parameters in these animals at the beginning of the tests. Mineral analysis of blood samples in the treatment group presented an increase in the levels of copper, potassium, iron, zinc, and manganese while in animals of the control groups there was an increase in sodium, calcium, and phosphorus. According to the blood serum and hair analysis, copper in the nanodispersed state indicated antagonistic effects on boron, silicon, antimony, molybdenum of the treatment group and there was a synergist in aluminum, titanium, manganese, cobalt, iron, and potassium levels compared to the beginning of the experiment. The obtained results indicated that the addition of copper nanopowder to the diet of experimental animals increased the growth, stimulated the function of hematopoiesis, and improved the characteristics of mineral metabolism of the Holstein heifers.
\end{abstract}

Keywords: Copper nanopowder, Cattle, Mineral metabolism, Physiological characteristics

\section{INTRODUCTION}

One of the main tasks in feeding farm animals is the development of the physiological and biological mechanisms of their high productivity. The basis of modern livestock production and biotechnology includes the determination of factors affecting the quantity and quality of products as well as the investigation of the necessary conditions for the maximum manifestation of the genetic potential by changing the compositions of the diet (Arsanukaev, 2005). At the present stage of animal husbandry development, new biologically active additives are developed and introduced into the diet of animals to enhance physiological processes and improve the quality of products (Natyrov and Arilov, 2002; Arsanukaev, 2005; Zaynalabdieva et al., 2014).

Among the substances that play an important role in farm animal nutrition, a significant place is taken by micronutrients, which are necessary for growth and reproduction (Myazin et al., 2006). The main source of micronutrients for animals is feed. However, the mineral composition of the feed depends on the type of soil, climatic conditions, and agrochemical measures (Myazin et al., 2006; Klyshevskaya, 2010; Dubovik and Dubovik, 2016).

Therefore, a lack or excess of some elements in a diet can lead to a decrease in productivity, deterioration in product quality, and the efficiency of feed use (Demidyuk, 1984). In zootechnical practice, inorganic salt types, such as sulfate, carbonate, chloride, and phosphate, are used to fill the deficit of mineral substances in the diet of farm animals. The zootechnical practice has several shortcomings in satisfying the physiological and biochemical criteria for the compatibility and combining ability of bioelements at different stages of metabolism. Some of shortcomings can be inorganic salts which are toxic and poorly absorbed by the digestion system. (Demidyuk, 1984; Antonovich et al., 2005).

Extensive research has been carried out to improve the technology of micronutrient in farm animal nutrition, especially on the integration of micronutrients complexes from natural, synthetic, and microbial origins into the diet (Bogoslovskaya et al., 2009; Timasheva et al., 2014; Chernova et al., 2015). 
An alternative to traditional forms of micronutrients can be nanopreparations containing metals (iron, cobult and copper) in the form of nanosized particles. The Scientific and Educational Center "Nano- and Biotechnologies" at Ryazan State Agrotechnological University, Russia, is studying the biological activity of metal nanopowders in various agricultural sectors (Polischuk et al., 2015a; Polischuk et al., 2018; Churilov et al., 2019), including the feeding of highly productive animals with the ability to catalyze biochemical processes in the body and increase metabolism (Nazarova et al., 2014; Miroshnikova et al., 2015; Sizova et al., 2016). With this background in mind, The aim of current study was to avaluate the effect of copper nanopowder on the mineral metabolism indicators during growth process of Holstein heifers.

\section{MATERIALS AND METHODS}

\section{Ethical approval}

The present study study used the following methods to reduce the pain and suffering of the experimental animals. The most humane and sparing methods and procedures were used towards animals to prevent their pain and suffering. Any painful procedures with animals were carried out according to the guidelines and standards, such as European Convention for the Protection of Vertebrate Animals Used for Experimental and other Scientific Purposes (ETS 123). Strasbourg, 1986. Directive of the European Parliament and the Council of the EU 2010/63/EU of September 22, 2010, on the protection of animals used for scientific research.

\section{Experimental groups}

The current research was conducted during 2016-2017 and placed at the Ryazan State Agrotechnological University named P.A. Kostychev and the livestocks were farm «Rassvet» in the Ryazan region, Russia. The samples of the study included a total number of 14 heifers of Holstein breed with black and white coats. The experimental animals were selected according to the principle of balanced analog groups by considering gender, age (1 month), breed and weight $(57.5-60.2 \mathrm{~kg})$. The samples were kept in similar conditions of feeding and management. The general research scheme is presented in Table 1. At the beginning of the research, the main diet consisted of cow's milk, after the age of 3 month, the basic diet of animals consisted of a combined type of feeding including grass, corn silage, haylage, compound feed and metal salts. The diet corresponded to the needs of the animals and physiological norms. The blood samples were subjected to the blood analysis at SHI "Ryazan Vet Laboratory". The analysis of the hair was carried out in the laboratory of the National Agency of Clinical Pharmacology and Pharmacy LLC, Moscow, Russia. The blood tests were performed before the study and 12 months after the study, the content of minerals in the blood serum of the animals was studied before the study and 6 months after it, the mineral composition of the wool was studied before the study and 40 days after it. The animals were weighed before the study (aged 1 month) and at the age of 2, 3, 4, 5, 7 and 11 month.

The employed experimental cuprum nanopowder $(\mathrm{NP} \mathrm{Cu}$ ) were produced at NITU MISiS with characteristics including finely-divided, homogeneous, dark-red powder and without any foreign particles, $99.98 \%$ pure. The average size of the particles were $20-40 \mathrm{~nm}$. The metal suspension was treated with ultrasound in aqueous media to create a biologically active ultradispersed system. Holstein heifers of Control and treatment groups were kept in separate houses (Figures 1 and 2).

Table 1. Experimental groups, duration and conditions

\begin{tabular}{lccc}
\hline Groups & $\begin{array}{c}\text { Number of } \\
\text { Animals }\end{array}$ & $\begin{array}{c}\text { Experiment } \\
\text { Duration }\end{array}$ & Experimental Conditions \\
\hline Control & 7 & 12 months & Basic Diet (BD) \\
Treatment & 7 & 12 months & BD + NP of cuprum $(0.04 \mathrm{mg} / \mathrm{kg}$ of live weight a day in 2, 4, 6, 9 months of life $)$ \\
\hline
\end{tabular}

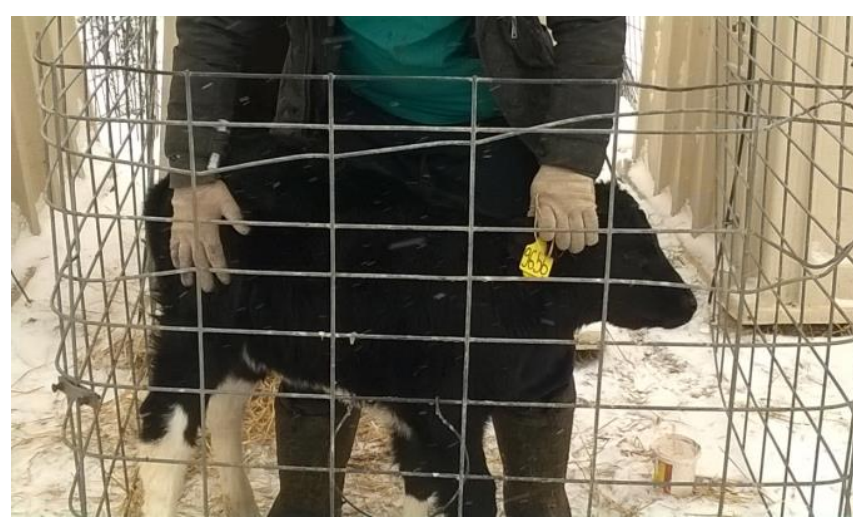

Figure 1. A Holstein heifer in control group did not receive cuprum nanopowders at the the first month of the experiment.

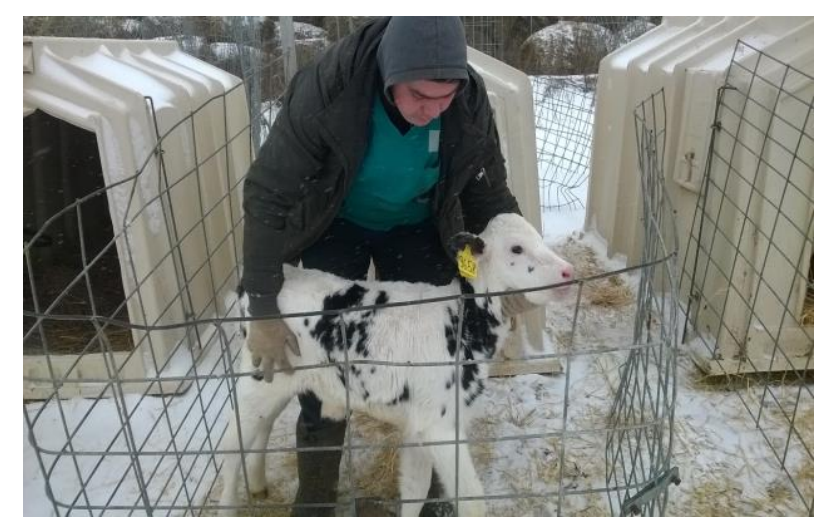

Figure 2. A Holstein heifer in treatment group received cuprum nanopowders at the first month of the experiment. 


\section{Experimental procedure}

For animals from the age of 1 month, an aqueous suspension of a dietary copper nanoparticles supplement in a dose of $0.04 \mathrm{mg} / \mathrm{kg}$ was orally administered on daily basis by considering the live weight. The suspension was administered during the second, fourth, sixth, ninth, and eleventh month of age, due to the high chemical activity of the nanoparticles and prolonged action, confirmed by previous studies (Polischuk et al., 2015b; Makarov et al., 2017; Nazarova et al., 2019). The weight of the control and treatment groups was measured in kg every month (Graph 1).

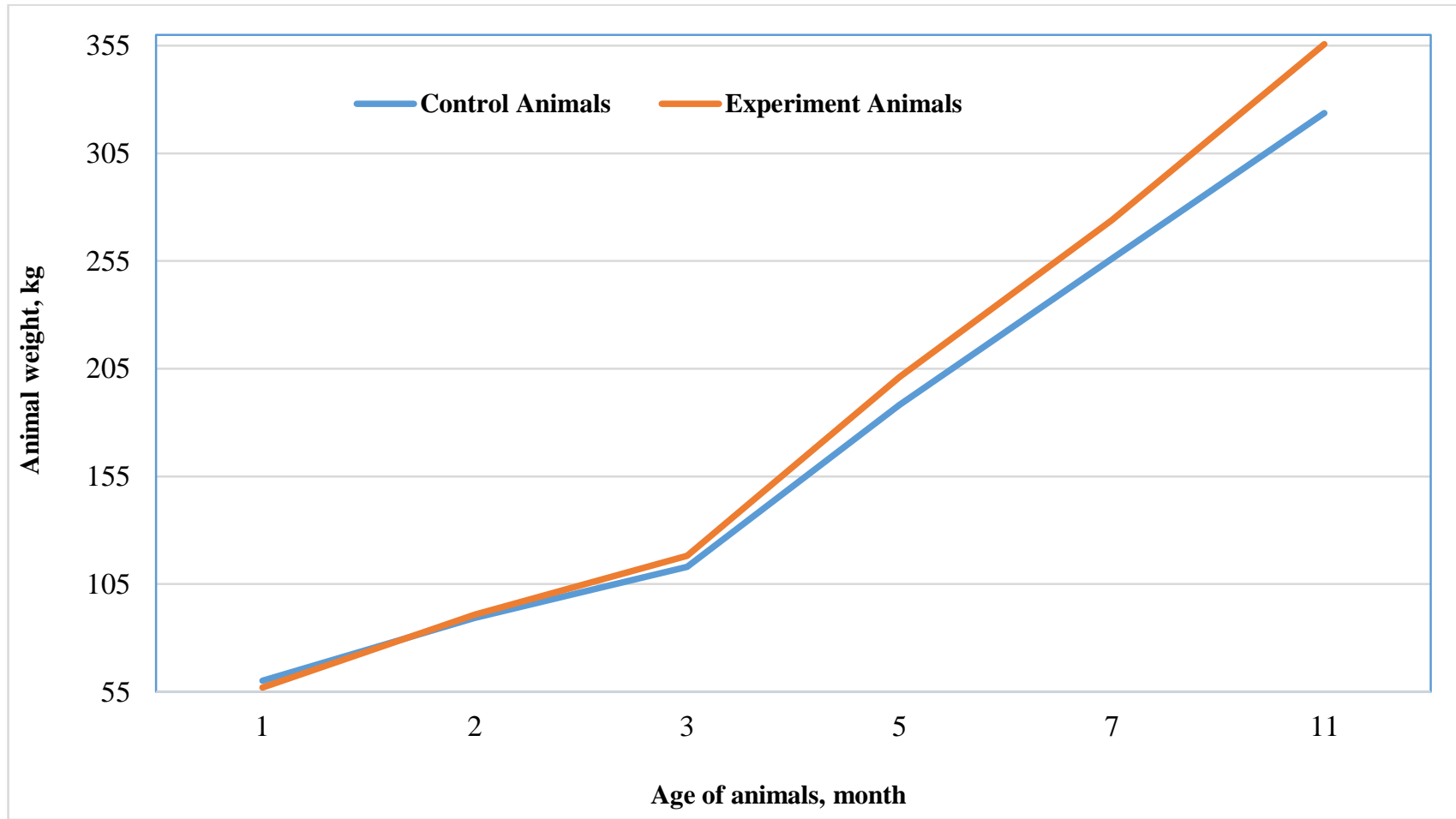

Graph 1. The weight of Holstein heifers of the control and treatment groups during experimental period.

\section{Statistycal analysis}

The statistical presecure of current study included processing the experimental data with the ranging method (ranging of odd quantitative parameters) for balanced analogues-groups by $K$. White $(\mathrm{p} \leq 0.05)$.

\section{RESULTS AND DISCUSSION}

The obtained results indicated that the diet of young Holstein heifers supplemented with copper nanoparticles had a significant effect $(\mathrm{p} \leq 0.05)$ on the mass weight of experimental animals.In the present study, an increase in live weight gain was observed in heifers treated with copper nanoparticles. Four months after the initiation of the study, the increase in live weight was $5.8 \%$, and by the 11 th month, it was $9.8 \%$, compared to the control group. The reason for this was the influence of copper on the absorption of calcium and phosphorus since there was active development of the skeleton during this period. Therefore, the use of the drug with copper nanoparticles ensured stable and intensive growth of animals.

Grozhevskaya (1973) indicated that under the influence of feeding copper sulfate to cows, a direct relationship was observed between an increase in the level of red blood cells and the amount of total protein and carotene. The obtained results indicated a simultaneous decrease in iodine and phosphorus with an increase in red blood cells and glucose in the blood samples of experimental animals of the treatment group. It is important to note that even a general increase in blood glucose of heifers led to a decrease in the level of ketone bodies. It is known that copper in the presence of iron is involved in the formation of hemoglobin in the blood and contributes to the transit of iron into the bone marrow (Overton and Yasui, 2014). Copper stimulates the formation of ossein, contributes to the normal development of bone tissue, and also affects the deposition of calcium and phosphorus, and the metabolism of carbohydrates, lipids, proteins, and minerals (Overton and Yasui, 2014). Glucose is a source of energy for almost all crucial physiological processes. Due to lack of glucose the animal body tries to compensate the energy deficit by transforming body fat into fatty acids. Decreasing of total number of blood protein is accompanied by a decrease in the body weight of cows and their reproductive abilities (Skopichev and Yakovlev, 2008).

In the course of the experiment, the main paraclinical scores of experimental heifers' blood samples were determined (Table 2). In control group, by the 12th month of the experiment, there was a slight increase in the level of 
red blood cells, hemoglobin, and platelets, which was associated with the natural processes of growth and development of young animals. The copper nanopowder treatmen group presented an increase in red blood cells (a significant increase of $14.7 \%$ ) and hemoglobin (by 11.2\%) ( $\mathrm{p} \leq 0.05$ ), compared with the beginning of the experiment, which in turn, affected the increase in hematocrit (a significant increase of $3.8 \%$, compared to the beginning of the experiment) (p $\leq$ 0.05). This finding was associated with the fact that copper nanoparticles are able to activate intracellular biochemical processes leading to requirement of a higher supply of oxygen for the tissues. The platelet content increased slightly, but this was observed both in the control and treatment groups, which was associated with the growth of animals and was independent of the introduction of nanoparticles. At the next stage of the study, the effect of copper nanopowder on the characteristics of the mineral metabolism of Holstein heifers breed during the growth of animals was studied. The blood mineral composition of the control and experimental animals was estimated before the start of the experiment and after six months (Table 3).

Table 2. Paraclinical scores of experimental Holstein heifers' blood samples

\begin{tabular}{|c|c|c|c|c|}
\hline \multirow{2}{*}{ Scores } & \multicolumn{2}{|c|}{ Control group } & \multicolumn{2}{|c|}{$\begin{array}{c}\text { Treatment group } \\
\text { (copper nanopowder) }\end{array}$} \\
\hline & $\begin{array}{l}\text { At the beginning of } \\
\text { the experiment }\end{array}$ & After 12 months & $\begin{array}{l}\text { At the beginning of } \\
\text { the experiment }\end{array}$ & After 12 months \\
\hline White blood cells, $10^{9} / 1$ & $7.9 \pm 0.1$ & $7.5 \pm 0.4$ & $7.5 \pm 0.5$ & $7.9 \pm 0.4$ \\
\hline Erythrocytes, $10^{12} / 1$ & $10.5 \pm 0.4$ & $11.3 \pm 0.3$ & $9.5 \pm 0.5$ & $11.8 \pm 0.3 * *$ \\
\hline Hemoglobin, g / 1 & $105 \pm 2$ & $115 \pm 5$ & $107.5 \pm 3.3$ & $119.9 \pm 5.1$ \\
\hline Hematocrit, $\%$ & $31.3 \pm 0.4$ & $34.2 \pm 0.6$ & $30.9 \pm 0.3$ & $34.7 \pm 0.6^{* * *}$ \\
\hline The number of platelets, $\mathrm{mln} / 1$ & $310.7 \pm 7.8$ & $327.0 \pm 6.5$ & $317.5 \pm 5.8$ & $333.7 \pm 10.2$ \\
\hline
\end{tabular}

Table 3. The content of minerals and alkaline phosphatase in the blood serum of experimental Holstein heifers

\begin{tabular}{|c|c|c|c|c|}
\hline \multirow{2}{*}{ Blood characteristics } & \multicolumn{2}{|c|}{ Control group } & \multicolumn{2}{|c|}{$\begin{array}{c}\text { Treatment group } \\
\text { (copper nanopowder) }\end{array}$} \\
\hline & $\begin{array}{l}\text { Before the } \\
\text { experiment }\end{array}$ & After 6 months & $\begin{array}{l}\text { Before the } \\
\text { experiment }\end{array}$ & After 6 months \\
\hline Calcium. mmol / L & $2.80 \pm 0.04$ & $2.95 \pm 0.05$ & $2.96 \pm 0.08$ & $2.93 \pm 0.05$ \\
\hline Phosphorus. mol / L & $1.75 \pm 0.04$ & $1.90 \pm 0.03^{*}$ & $2.31 \pm 0.02$ & $2.28 \pm 0.01$ \\
\hline Alkaline phosphatase. IU/L & $104 \pm 3.6$ & $118 \pm 3.4^{*}$ & $173.3 \pm 3.9$ & $211.6 \pm 5.0^{* * * *}$ \\
\hline Copper. mmol / L & $0.51 \pm 0.002$ & $0.42 \pm 0.008$ & $0.57 \pm 0.011$ & $0.72 \pm 0.010^{* * *}$ \\
\hline Potassium. mmol / L & $3.9 \pm 0.04$ & $3.1 \pm 0.01^{* * *}$ & $4.08 \pm 0.14$ & $4.29 \pm 0.15$ \\
\hline Sodium. mmol / L & $130.5 \pm 4.4$ & $151.8 \pm 3.1^{* *}$ & $155.6 \pm 4.6$ & $145.9 \pm 1.3$ \\
\hline Iron. mmol / L & $25.9 \pm 0.4$ & $20.3 \pm 0.7^{* * *}$ & $18.3 \pm 0.3$ & $29.1 \pm 0.5^{* * *}$ \\
\hline Magnesium. mmol / L & $0.86 \pm 0.005$ & $0.75 \pm 0.003^{* * *}$ & $0.88 \pm 0.002$ & $0.85 \pm 0.001^{* * *}$ \\
\hline Zinc. micromol / 1 & $19.8 \pm 0.7$ & $16.5 \pm 0.4^{* *}$ & $11.6 \pm 0.3$ & $15.4 \pm 0.9^{* *}$ \\
\hline Manganese. mmol / L & $0.043 \pm 0.007$ & $0.038 \pm 0.002$ & $0.03 \pm 0.001$ & $0.05 \pm 0.004^{* *}$ \\
\hline Chlorides. mmol / L & $101.1 \pm 2.5$ & $112.4 \pm 1.3^{* *}$ & $99.6 \pm 1.7$ & $119.4 \pm 2.1^{* * *}$ \\
\hline
\end{tabular}
${ }^{*}: \mathrm{p} \leq 0.05 ;{ }^{* *}: \mathrm{p} \leq 0.01 ;{ }^{* * * *}: \mathrm{p} \leq 0.001$

Six months after the start of the experiment, an increase in the content of calcium $(+5.4 \%)$ and phosphorus $(+$ $8.6 \%$ ) was observed in control group, which was primarily associated with intensive growth of heifers in the first month of age. The content of sodium $(+16.3 \%)$ and chloride ions $(+11.2 \%)$ also increased. There was more copper in the tissues of young animals than in the tissues of adult animals, for example, there was $14 \mathrm{mg} / \mathrm{kg}$ copper content in the muscles of calves, but $0.5 \mathrm{mg} / \mathrm{kg}$ in colostrum and $0.05 \mathrm{~m} / \mathrm{kg}$ in milk of adult animals. The need for copper in cattle is higher than in other animal species, especially in range management. Copper deficiency causes growth retardation and decreased productivity. Moreover, it has a significant effect on the color of the coat, which can transform gray or brown, or become dirty yellow, and it increases the fragility of bones (Bolotnov, 2002). Excessive consumption of copper would manifest itself in the form of lipase taste of milk when $80 \mathrm{mg}$ of copper was included per $1 \mathrm{~kg}$ of dry matter of the diet (Bolotnov, 2002). Several other changes were observed in the blood samples of copper nanopowder treatment group. About six month after the start of the experiment, an increase in the level of alkaline phosphatase (a significant increase of $22.1 \%$ compared from the beginning of the experiment), copper $(+26.3 \%)$, potassium $(+5.1 \%)$, iron $(+59 \%)$, zinc $(+$ $32.7 \%$ ), and manganese $(+66 \%)$ were observed $(\mathrm{p} \leq 0.05)$. The sodium content decreased by $6.2 \%$, the magnesium content did not change, which supported the data from the changes in the mineral composition of the hair. Before the start of the experiment, hair samples were taken from control and treatment group. For about 40 days after adding nanocopper in the diet, re-sampling of hair was carried out to analyze its mineral composition. A tendency of changes in 
the content of elements was also observed in the analysis of the mineral composition of Holstein heifer's hair which was similar to the changes in the blood (Table 4).

Table 4. Mineral composition of experimental Holstein heifers' hair $(\mu \mathrm{g} / \mathrm{l})$

\begin{tabular}{|c|c|c|c|c|}
\hline \multirow{2}{*}{ Elements } & \multicolumn{2}{|c|}{ Control } & \multicolumn{2}{|c|}{ Copper nanopowder } \\
\hline & Before the experiment & After 40 days & Before the experiment & After 40 days \\
\hline Lithium & $0.158 \pm 0.0022$ & $0.040 \pm 0.0006^{* * *}$ & $0.047 \pm 0.0007$ & $0.007 \pm 0.0001^{* * * *}$ \\
\hline Boron & $2.342 \pm 0.033$ & $2.670 \pm 0.038^{* * * *}$ & $2.413 \pm 0.034$ & $0.141 \pm 0.002^{* * * *}$ \\
\hline Aluminum & $14.247 \pm 1.213$ & $9.369 \pm 1.133^{* * * *}$ & $11.907 \pm 0.170$ & $15.537 \pm 0.221^{* * *}$ \\
\hline Silicon & $14.460 \pm 1.207$ & $32.570 \pm 2.465^{* * *}$ & $22.700 \pm 3.324$ & $13.900 \pm 1.198^{*}$ \\
\hline Titanium & $0.008 \pm 0.000001$ & $0.008 \pm 0.000002$ & $0.006 \pm 0.00008$ & $0.009 \pm 0.0001^{* * *}$ \\
\hline Manganese & $1.139 \pm 0.016$ & $1.112 \pm 0.015$ & $0.751 \pm 0.010$ & $2.084 \pm 0.029^{* * *}$ \\
\hline Chromium & $0.858 \pm 0.0022$ & $0.874 \pm 0.0124$ & $0.689 \pm 0.009$ & $0.763 \pm 0.010^{* *}$ \\
\hline Cobalt & $0.021 \pm 0.0003$ & $0.027 \pm 0.0004^{* * *}$ & $0.016 \pm 0.0002$ & $0.158 \pm 0.0022^{* * *}$ \\
\hline Nickel & $0.354 \pm 0.005$ & $0.183 \pm 0.002^{* * * *}$ & $0.154 \pm 0.002$ & $0.187 \pm 0.003^{* * *}$ \\
\hline Arsenic & $0.034 \pm 0.001$ & $0.037 \pm 0.003$ & $0.029 \pm 0.0004$ & $0.038 \pm 0.0005^{* * *}$ \\
\hline Selenium & $0.939 \pm 0.013$ & $0.957 \pm 0.017$ & $0.803 \pm 0.011$ & $0.820 \pm 0.012$ \\
\hline Cadmium & $0.003 \pm 0.00004$ & $0.003 \pm 0.00006$ & $0.001 \pm 0.0001$ & $0.005 \pm 0.0007^{* * *}$ \\
\hline Antimony & $0.005 \pm 0.0007$ & $0.024 \pm 0.0030^{* * *}$ & $0.008 \pm 0.0001$ & $0.006 \pm 0.00008$ \\
\hline Mercury & $0.115 \pm 0.0016$ & $0.043 \pm 0.0006$ & $0.036 \pm 0.0005$ & $0.061 \pm 0.0009$ \\
\hline Lead & $0.261 \pm 0.003$ & $0.401 \pm 0.006$ & $0.241 \pm 0.003$ & $0.289 \pm 0.004$ \\
\hline Copper & $18.700 \pm 0.267$ & $12.870 \pm 0.183$ & $11.440 \pm 0.163$ & $11.900 \pm 0.170$ \\
\hline Iron & $27.600 \pm 0.394$ & $21.900 \pm 0.312$ & $18.700 \pm 0.267$ & $33.500 \pm 0.478$ \\
\hline Zinc & $135.120 \pm 1.930$ & $122.100 \pm 1.744$ & $118.320 \pm 1.690$ & $125.040 \pm 1.786$ \\
\hline Sodium & $645.700 \pm 9.224$ & $794.600 \pm 11.351$ & $500.000 \pm 7.142$ & $449.100 \pm 6.415$ \\
\hline Magnesium & $32.550 \pm 0.465$ & $29.767 \pm 0.425$ & $35.083 \pm 0.501$ & $30.550 \pm 0.437$ \\
\hline Potassium & $1244.020 \pm 17.771$ & $1162.390 \pm 16.605$ & $718.950 \pm 10.270$ & $801.170 \pm 11.445$ \\
\hline Calcium & $846.000 \pm 12.085$ & $999.000 \pm 14.271$ & $1034.000 \pm 14.771$ & $779.00 \pm 11.128$ \\
\hline Molybdenum & $0.090 \pm 0.001$ & $0.127 \pm 0.002$ & $0.094 \pm 0.001$ & $0.134 \pm 0.002$ \\
\hline
\end{tabular}

The following changes occurred in the hair of control animals during the experiment: there was a decrease in lithium $(-74.7 \%)$, aluminum (-34.2\%), nickel (-48.3\%), mercury (-62.6\%), copper $(-31.2 \%)$, iron (-20.6\%), zinc (-9.6\%), magnesium $(-8.5 \%)$, and potassium $(-6.6 \%)$. At the same time, there was an increase in the content of the following elements: silicon $(+125.2 \%)$, cobalt $(+28.6 \%)$, antimony $(+380 \%)$, lead $(+53.6 \%)$, sodium $(+23.1 \%)$, calcium $(+18.1 \%)$, and molybdenum $(+41.1 \%)$.

Considering the fact that the diet of control and treatment groups was the same, except for the addition of copper nanopowder, then changes in the mineral composition of the hair coat and significant differences $(p \leq 0.05)$ in the content of blood minerals were considered solely as a result of exposure to copper nanoparticles. General changes in the hair of control and treatment group were observed with a decrease in lithium levels and an increase in silicon and cobalt. Compared to the control group, nanopowder of copper treatment group presented antagonistic action with respect to boron $(-94.2 \%)$, silicon $(-38.8 \%)$, antimony $(-25 \%)$, sodium $(-10.2 \%)$, molybdenum $(-86.7 \%)$ in comparison to the data from beginning of the experiment. The decrease in molybdenum was consistent with the antagonistic effect of copper in ionic form.

Furthermore, copper nanopowder contributed to an increase in the content of aluminum $(+30.5 \%)$, titanium $(+$ $50 \%)$, manganese $(+177.5 \%)$, cobalt $(9$ times), nickel $(+21.4 \%)$, mercury $(+69.4 \%)$, copper $(+4 \%)$, iron $(+79.1 \%)$, and potassium $(+11.4 \%)$, compared to the beginning of the experiment. The nanoscale effect of copper was observed by an increase in the uptake of cadmium (4 times) and zinc (+5.7\%). It is known that copper in ionic form was an antagonist of these metals. Copper and calcium in the form of salts were neutral to each other, and copper nanoparticles reduced calcium absorption by $24.7 \%$.

Copper nanoparticles affected the increase of iron and cobalt content in the blood of animals. The reason is that these metals are synergistic in ionic form, but their combined use does not lead to such a significant increase in the assimilation and accumulation of each other in animals (Voynar, 1960).

The main place for copper absorption in animals is the small intestine and stomach. The copper absorbtion does not occur only as a result of simple diffusion but also by actively transferring the micronutrient through the intestinal wall and the active transferring increases significantly with deficiency of micronutrient (Kuznetsov and Kuznetsov, 2003). The copper in combination with aminoacids, dipeptides and polypeptides is absorbed better than in the form of sulfate and while the molecular weight of the complexes increases then the absorption decreases (Kuznetsov and Kuznetsov, 
2003). The mediator for absorption of copper, as well as zinc and cadmium, is a low molecular weight protein of the intestinal wall called metallothionein, which increases absorption in a passive way, linking the element to SH-groups and preparing it for further transfer. In addition, it can block absorption and protect the body from reaching toxic levels of metal (Kuznetsov and Kuznetsov, 2003). The absorption of copper is influenced by many feed factors, specifically protein. An increase in the protein level of the diet reduces its accumulation in the liver. Some heavy metals (such as lead, cadmium, mercury, silver, zinc, and arsenic) compete with copper upon absorptionwhich leaded to insufficiency of copper (Kuznetsov and Kuznetsov, 2003).

In general, the obtained results indicated that copper particles in the nanodispersed state activated the mineral metabolism in the body of Hostein heifers, contributing to the assimilation and accumulation of mineral substances. It should be noted that the effect of copper nanoparticles were significantly different from that copper in ionic form, which was associated with the size of the particles, their charge, the concentration, and the method of preparation.

\section{CONCLUSION}

According to the results of the current study, it can be concluded that the addition of copper nanopowder to the cattle diet stimulated the blood formation function of the body, which was manifested in an increase in red blood cells by $14.7 \%$ and hemoglobin content by $11.2 \%$. Based on the blood serum and hair analysis and considering the theory of antagonistic and synergistic interaction of micronutrients, it was indicated that the characteristics of the mineral metabolism of Holstein cattle became significantly more active under the influence of copper nanoparticles. The analysis of the mineral composition of animal hair revealed that the addition of copper nanopowder led to an antagonistic effect on boron, silicon, antimony, and molybdenum. In addition, copper in the nanodispersed state presented itself as a synergist of aluminum, titanium, manganese, cobalt, iron, and potassium, compared to the beginning of the experiment. Additionally it can be concluded that copper nanopowder can be used as a biologically active additive in the diet of young cattle, which improves the general physiological state and as a stimulator of mineral metabolism.

\section{DECLARATIONS}

\section{Authors' contribution}

Anna A. Nazarova and Irina A. Stepanova collected data and designed the study. Anna A. Nazarova, Irina A. Stepanova, and Mikhail V. Arisov analyzed data and wrote the draft of manuscript. All authors read and approved the final manuscript.

\section{Competing interests}

The authors did not have any conflict of interests.

\section{Acknowledgements}

The authors are grateful to SHI "Ryazan Vet Laboratory", laboratory of the National Agency of Clinical Pharmacology and Pharmacy LLC, NITU MISiS for their assistance in data collection.

\section{Consent to publish}

The authors approved and agreed to publish the manuscript

\section{REFERENCES}

Antonovich EA, Podushnyak AE, and Schutskaya TA (2005). Toxicity of copper and its compounds. Institute of Environmental Hygiene and Toxicology. L.I. Medveda, Kiev., p. 28. Available at: http://www.medved.kiev.ua/arhiv_mg/stat_99/99_3_1.htm

Arsanukaev D (2005). Efficiency of microelement nutrition of male calves. Dairy and beef cattle breeding, 8: 12-14. Available at: http://foliant.ru/catalog/psulibr?SHOW_ONE_BOOK+21F354

Bogoslovskaya OA, Sizova EA, Polyakova VS, Miroshnikov SA, Leipunsky IO, Olkhovskaya IP and Glushchenko NN (2009). Studying the safety of administering copper nanoparticles with various physicochemical characteristics into the animal organism. Herald of the Orenburg State University, 2: 124-127. Available at: https://elibrary.ru/item.asp?id=13009569

Bolotnov L (2002). Minerals and vitamins in the diets of lactating cows. Compound feed, 4: 52-53. Available at: https://elibrary.ru/title_about.asp?id=9589

Chernova EL, Yastrebova OL and Chernov IS (2015). The effect of organic salts of biometals on cicatricial digestion and milk production of cows. Scientific notes of the Kazan State Academy of Veterinary Medicine named after N.E. Bauman, 221 (1): 246-249. Available at: https://elibrary.ru/item.asp?id=23221254

Churilov GI, Churilov DG, Nazarova AA, Polischuk SD, Churilova VV, Borychev SN, and Byshov NV (2019). Dinamics of accumulating pollutants and essential elements in the process of plant growth and development. International Journal Nanotechnology, 16 (1/2/3): 42-59. DOI: http://doi.org./10.1504/IJNT.2019.102391

Demidyuk AA (1984). Influence of Cuprum, Cobalt and Iodine Compensation in Diets on Metabolic Processes and Cows' Milk Productivity. Candidate of Biological Science Dissertation: 03.00.04, Lvov. DOI: http://doi.org./10.15389/ agrobiology.2016.6.903rus

Dubovik DV, and Dubovik EV (2016). The effect of mineral fertilizers on the content of heavy metals in the soil on the slopes. Bulletin of the Kursk State Agricultural Academy, 4: 60-62. Available at: https://elibrary.ru/download/elibrary_26642836_10621774.pdf

Grozhevskaya SB (1973). The biological significance of copper for the body of cattle. Issues of feeding agricultural animals. Proceedings of the Kirov and Perm Agricultural Institute, pp.12-19. 
Klyshevskaya SV (2010). Change in the content of micronutrients in soils during land reclamation. Bulletin of KrasGAU, 10: 45-48. Available at: https://elibrary.ru/item.asp?id=15486476

Kuznetsov S, and Kuznetsov A (2003). Micronutrients in animal feeding. Zhivotnovodstvo Rossii, 3: 16-18. Available at: https://fermer.ru/sovet/zhivotnovodstvo/80766

Makarov PM, Stepanova IA, Nazarova AA, Polischuk SD, and Churilov GI (2017). Physiological and biochemical parameters of holstein heifers when adding to their diet bio-drugs containing cuprum and cobalt nanoparticles. Nano Hybrids and Compos, 13: 123-129. DOI http://doi.org./10.4028/www.scientific.net/NHC.13.123

Miroshnikova EP, Arinzhanov A, Kilyakova T, Sizova EA, and Miroshnikov SA (2015). Antagonism metal alloy nanoparticles of iron and cobalt: impact on micronutrient metabolism in carp and chicken. Human \& Veterinary Medicine, 7 (4): 253-259. Available at: http://www.hvm.bioflux.com.ro/docs/2015.253-259.pdf

Myazin NG, Pavlov RA, and Sheina VV (2006). The effect of fertilizers on the accumulation of nitrates and heavy metals in soil and plants and on the productivity of a unit of grain-crop crop rotation. Agrochemistry, 2:22-29. Available at: https://www.elibrary.ru/item.asp?id=9217543

Natyrov AK, and Arilov AN (2002). Rationing of minerals in the diets of meat-breed male calves. Zootechnics, 5: 19-20. Available at: https://www.elibrary.ru/item.asp?id=9124894

Nazarova AA, Polishchuk SD, Stepanova IA, Churilov GI, Nguyen HC, and Ngo QB (2014). Biosafety of the application of biogenic nanometal powders in husbandry. Advances in Natural Sciences: Nanoscience and Nanotechnology, 5(1): 13-15. Available at: DOI: http://doi.org./10.1088/2043-6262/5/1/015013

Nazarova AA, Stepanova IA, Churilov GI, Polischuk SD, Churilova VV, and Churilov DG (2019). Influence of copper nanopowder on parameters of carbohydrate and lipid metabolism of Holstein heifers. International Journal Nanotechnology, 16: 122-132. DOI: http://doi.org./10.1504/IJNT.2019.102399

Overton TR, and Yasui T (2014). Practical applications of trace minerals for dairy cattle. Journal of Animal Science, 92(2): 416-426. DOI http://doi.org./10.2527/jas.2013-7145

Polischuk SD, Churilov GI, Borychev SN, Byshov NV, and Nazarova AA (2018). Nanopowders of cuprum, cobalt and their oxides used in the intensive technology for growing cucumbers. International Journal Nanotechnology, 15: 352-369. DOI: http://doi.org./10.1504/IJNT.2018.094792

Polischuk SD, Nazarova AA, and Stepanova IA (2015a). Toxicological characterization of bio-active drugs on basis of Iron Fe, Co, and Copper Cu nanopowders. IOP Conference Series.: Materials Science and Engineering,98: 012037. DOI: http://doi.org./10.1088/1757-899X/98/1/012037

Polischuk SD, Nazarova AA, Kutskir MV, Churilov DG, Ivanycheva YN, Kiryshin VA, and Churilov GI (2015b). Ecologic-biological effects of cobalt, cuprum, copper oxide nano-powders and humic acids on wheat seeds. Modern Applied Science, 9 (6): 354-364. DOI: http://dx.doi.org/10.5539/mas.v9n6p354

Sizova EA, Korolev VL, Makaev ShA, Miroshnikova EP, and Shakhov BA (2016). Morpho-biochemical parameters of broilers' blood when correcting the diet with salts and nanoparticles of $\mathrm{Cu}$. Agricultural Biology, 51(6): 903-911. DOI: http://dx.doi.org/10.15389/agrobiology.2016.6.903rus

Skopichev VG, and Yakovlev VI (2008). Special physiology. Part 2. Food-producing animals physiology. Moscow, Russia. P. 555. Available at: https://www.elibrary.ru/item.asp?id=19511352

Voynar AI (1960). Biological role of micronutrients in animals and humans. Publishing house $2^{\text {nd }}$, Moscow. Available at: https://rusneb.ru/catalog/002072 000044_ARONBRU \%D0\%90\%D1\%80\%D1\%85\%D0\%B0\%D0\%BD\%D0\%B3\%D0\%B5\%D0\%BB\%D1\%8C\%D1\%81\%D0\%BA\%D0\%B0\%D1\%8F\%20\%D0 \%9E\%D0\%9D\%D0\%91_DOLIB_-080502/

Zaynalabdieva KhM, Arsanukaev DL, and Alekseeva LV (2014). Influence of Microelements on Hematological Parameters of Pigs. Izvestiya of Orenburg State Agrarian University, 2: 189-190. Available at: https://www.elibrary.ru/item.asp?id=21646802

Timasheva AB, Miroshnikov SV, Notova SV, and Lebedev SV (2014). Influence of Asparginat and Cuprum Nanoparticles in Biotic Dose on Element Status of LabAnimals. Microelements in Medicine, 15(2): 29-33. Available at: https://www.elibrary.ru/item.asp?id=21692640 